\title{
Socio Economic Profile of Buffalo Farmers in Guntur and Prakasam Districts of Andhra Pradesh, India
}

\author{
D.V. Sivaji ${ }^{1^{*}}$, K. Natchimuthu ${ }^{2}$, S. Ramkumar ${ }^{2}$, D. Sreekumar ${ }^{2}$ and R. Ganesan ${ }^{2}$ \\ ${ }^{1}$ M.V.Sc in Veterinary and Animal Husbandry Extension, India \\ ${ }^{2}$ Faculty in Rajiv Gandhi Institute of Veterinary Education and Research, \\ Puducherry-605009, India \\ *Corresponding author
}

\section{A B S T R A C T}

\begin{tabular}{|l|}
\hline Ke y w or d s \\
Buffalo farming, Guntur, \\
$\begin{array}{l}\text { Prakasam, Andhra } \\
\text { Pradesh, Graded Murrah }\end{array}$ \\
\hline Article Info \\
\hline $\begin{array}{l}\text { Accepted: } \\
\text { 16 March } 2018 \\
\text { Available Online: } \\
\text { 10 April } 2018\end{array}$ \\
\hline
\end{tabular}

\section{Introduction}

Buffalo holds the greatest promise for food security in the $21^{\mathrm{st}}$ century as these animals form an integral part of the typical farming system in many regions of India. Buffalo is the largest capital asset as well as the friend of small farmers which is the back bone of rural economy in many parts of India (Manohar, 2012). According to the $19^{\text {th }}$ livestock census there is a total of 10.6 million buffaloes in Andhra Pradesh with milk production of 7.4 MTS (GOI, 2017). About 72 per cent of milk produced in the state comes from buffaloes. Presently, about 24 lakh families in Andhra Pradesh directly depend on buffalo rearing for their livelihood with an average herd size of 1.3 adult female buffalo (NSS, 2013).

\section{Materials and Methods}

Out of 13 districts of Andhra Pradesh, Guntur and Prakasam districts ranks as first and second in buffalo population and buffalo milk production. The study was conducted among buffalo farmers in Guntur and Prakasam districts of Andhra Pradesh. A total of 144 respondents identified by using multi stage random sampling technique. The data was collected through direct personal interview method by using structured schedule. 


\section{Results and Discussion}

Age

Majority of the respondents (44.44\%) were youth. The age of respondents ranged from 25 to 75 years with mean age of 44.8 years. It is inferred that more number of young respondents involved in buffalo rearing indicates the possibility of sustainability of buffalo rearing in the study area. This is supported the studies in Jammu \& Kashmir and Rajasthan by Debasish et al., (2010) and Upadhyay and Yadav (2015) respectively.

\section{Gender}

Majority of the respondents (56.94\%) were male in carried out the buffalo farming activities in the study area. The female male ratio of respondents was $1: 1.32$, which is not in line with the state sex ratio (1:1). This shows that there is a dominance of male respondents' involvement in buffalo rearing in the study area. These findings supported the findings of Desai (2011) and Swathi (2015) who found that majority of buffalo farmers were male respondents in South Gujarat and in Andhra Pradesh, respectively.

\section{Education level}

About one half of the respondents had no formal schooling, followed by 25.69 per cent of respondents had primary school education and about 15 per cent of respondents had secondary school education. It revealed that more number of respondents had primary education in Guntur district $(31.94 \%)$ than Prakasam district (19.44\%). The education level of respondents is less than the literacy rate of general public of these two districts (GoAP, 2015). This revealed that education had negative influence on undertaking buffalo rearing. Overall male respondents were more educated than the female respondents but in
Guntur district females were more educated than in Prakasam district. These results are in agreement with the findings of Swathi (2015) who found that 47 per cent of the buffalo farmers had no formal education in rural areas of Cuddapah district of Andhra Pradesh.

\section{Family size}

Majority of selected respondents (56.94\%) had large family with more than 4 members and about 43 per cent of respondents had small family. Average family size of respondents was 4.85. Gautam et al., (2007) and Vinothini (2010) observed that average family size of dairy farmers were 5 and 4.68 respectively. On an average number of other family members extending their help to respondent in buffalo rearing was 1.33 . These results are similar to the findings of Upadhyay and Yadav (2015) who found that majority of the dairy farmers had large family (54\%) followed by small $(46 \%)$ family in Bhilwari district of Rajasthan.

\section{Community}

About 39 per cent of respondents belonged to the forward community (OC) and 27.78 per cent of respondents belonged to the backward community (BC). Whereas, SC/ST community respondents involved in buffalo rearing was 33.33 per cent. Respondents from all communities were involved in buffalo rearing in Andhra Pradesh. The percentage of SC/ST population involved in buffalo rearing was more than the other communities. Cent per cent of respondents conformed that buffalo rearing is not a low status occupation or attached to any specific community. This indicates that, community is not a barrier for undertaking buffalo rearing in Andhra Pradesh. These results supported the findings of Gangasagare and Karanjkar (2009) in Maharashtra and Sudhir (2014) in Andhra Pradesh. 


\section{Major occupation}

Buffalo rearing was the major occupation for around 44 per cent of respondents followed by agriculture $(27.78 \%)$, agricultural labour (15.97\%), business (4.17\%) and miscellaneous occupations (7.64\%). About 56 per cent of respondents earned major portion of their income from buffalo rearing in Prakasam district and it was 33.33 per cent in Guntur district. In Guntur district, the agricultural crop residue paddy straw availability was more hence majority considered buffalo rearing as their supplementary occupation. But in Prakasam district, mostly dry land and more dependent on tube well for irrigation, pulses was their primary agricultural product, so majority considered buffalo rearing as their primary occupation. It is similar to the findings of Prasad et al., (2001) and Gautam et al., (2007) who reported that the dairying was the main occupation for about 60 per cent of milk producers in Andhra Pradesh and Uttar Pradesh respectively. But the results are contrary to the findings of Kishore et al., (2013) and Swathi (2015) in Andhra Pradesh and Ahirwar et al., (2010) in Maharashtra, who observed that primary occupation of the buffalo farmers was agriculture.

\section{Size of land holding}

About 34 per cent of respondents were small land holders and 26 per cent were landless. Large and medium land holding respondents were about 21 and 19 per cent respectively. Among the landless, half of them were SC/ST respondents. Small farmers were getting higher (Rs. 85,917) income from buffaloes followed by large farmers (Rs. 79,647) and landless farmers (Rs. 72,181). Medium farmers were getting only Rs. 55,326 from buffaloes. This less income to this medium farmers might be due to the more involvement in agriculture. The results are almost similar to the findings of Kishore et al., (2013) who observed that nearly one half of buffalo farmers had above 3 acres of land in Khammam district of Andhra Pradesh.

\section{Herd size and composition}

Data reveals that the average herd size was 5.42. Majority of the respondents $(62.50 \%)$ had maintained medium herd (size of 4 to 7 buffaloes). About 24 per cent respondents had small buffalo herd, remaining (13.89\%) had large buffalo herd. The mean lactating and dry buffaloes in herds were 2.57 and 0.95 respectively. Dry to lactating buffalo ratio was 1: 2.71. It is evident that distribution of dry buffaloes was more in Prakasam district than Guntur district. Similarly, ratio of dry to lactating buffaloes was less in Prakasam district. Majority of buffaloes reared by the respondents were graded Murrah (70.04\%) and 26.12 per cent were non-descript buffaloes. This might be due to more number of non-descript buffaloes in Prakasam district compared to Guntur district. Findings are similar to that of Suresh et al., (2013) who reported that most of the $(66 \%)$ dairy farmers maintained less than 3 lactating animals, of this graded Murrah and non-descript buffaloes were maintained by 66 per cent and 34 per cent of the dairy farmers respectively in Haryana. The results are contrary to the findings of Sinha et al., (2009) who observed that non-descript buffaloes were predominantly present in rural and semi urban areas, whereas, urban area had more Murrah buffaloes in Bareilly district of Uttar Pradesh.

\section{Annual family income}

The mean annual family income was Rs. $2,63,880$ and ranged from Rs. 35,000 to $15,50,000$. Only about 10 per cent of respondents belonged to low income group. Majority of the respondents (75.69\%) belonged to medium income group, followed 
by 13.89 per cent belonged to high income group with the income of above Rs. 4 lakhs. The sources of income for the high family income group were business or large farms or their children employed in government or in software companies. These results are in agreement with the study of Mande and Thombre (2009) in Maharashtra. But it is not in line with the findings of Vinothini (2010) and Rathod et al., (2013) who found that majority of dairy farmers belonged to the low family income group.

\section{Annual income from buffalo rearing}

About 51 per cent of the respondents obtained less than Rs. 50,000 from buffalo farming, which is classified as low income group. About 29 per cent of the respondents received more than Rs. 50,000 but less than Rs. 1 lakh which is considered as medium income and remaining $(20.14 \%)$ respondents received high income of more than Rs. 1 lakh from buffalo farming.

The mean income earned from the buffalo farming alone was Rs. 75,236. The respondents of Prakasam district were getting more income (Rs. 78,236) from buffaloes than those of Guntur district (Rs. 71,514). On an average, monthly the respondents were getting about Rs. 6,200 from buffaloes, which was apparently higher than agricultural labour earnings.

This indicates the importance of buffalo rearing in the study area. This findings support the results of Sudhir (2014) who found that income contributed by dairy farming was Rs. 75,206 in Prakasam district. Whereas, Swathi (2015) reported lower contribution of dairying (Rs. 49,483) in rural areas of Cuddapah district. However, income from dairy farming was quite substantial for majority of the respondents in Puducherry (Waldie and Ramkumar, 2002).

\section{Contribution of buffalo farming to the family income}

The mean contribution of buffalo farming to the family income was about 35 per cent. It is evident that mean contribution of buffalo income to family income was more in Prakasam district (39.24\%) than Guntur district $(30.35 \%)$. The finding is in contrast to the finding of Swathi (2015) who reported that the contribution of dairying to the total family income was 41 per cent in Cuddapah district of Andhra Pradesh. Similarly, Heffernan (2002) observed that majority of the families earned 60 per cent of the income from dairy farming in Orissa. The result is also not in line with Vinothini (2010) who reported that dairy farming contributed 19 per cent to the total family income of members of women dairy cooperative societies in Puducherry.

\section{Experience in buffalo rearing}

About 36 per cent of the respondents had less than 10 years of experience in buffalo rearing. Around 35 per cent of respondents had 11 to 20 years of experience and remaining 29.17 per cent of respondents had above 21 years of experience in buffalo rearing. The average experience in buffalo rearing was 14.86 years. The results are almost similar to the findings of the results also similar to the findings of Nataraju (2012) who reported that 53 per cent of dairy women had low level of experience in Chikmagalur district of Karnataka.

\section{Extension contact}

Majority of the respondents (57.64\%) had extension contact with para veterinarian with reference to buffalo rearing and 37.50 per cent had extension contact with veterinarian. This might be due to the availability of more number of para veterinarians than the veterinarians in both the districts. These 
results supported the observations of Swathi (2015) in Andhra Pradesh, that buffalo farmers had more extension contact with para veterinarians.

\section{Training undergone in buffalo rearing}

About 3 per cent of the respondents only had undergone training in buffalo rearing in the last one year. This might be due to the main focus of Animal Husbandry Department is on providing veterinary clinical services, animal health camps and deworming camps etc. on the other side, buffalo rearing was a traditional occupation for majority of the respondents, who might not have showed interest in undertaking training. These results are in line with the findings of Chandrasekar et al., (2017) who found that none of the dairy farmers undergone any type of training related to the dairy farming in Karnataka.

The results showed that buffalo farming is an occupation of young respondents with no formal schooling and small land owners belonging to all communities. It contributes $1 / 3^{\text {rd }}$ of their family income. Annual family income of buffalo farmers was Rs. 2,63,880 and from buffalo farming was Rs. 75,236. The study clearly reveals that in Guntur district buffalo farming was more of agriculture linked whereas in Prakasam district it is a primary occupation and also one of the major source of income.

\section{References}

$19^{\text {th }}$ Livestock census, 2012. Annual report. Department of Animal Husbandry, Dairying and Fisheries. Government of India.

Ahirwar, R.R., Singh, A., and Qureshi, MI.2010. A Study on Managemental Practices in Water Buffalo (Bubalus bubalus) in India, Buffalo Bulletin, 29(1): 43-51.
Chandrasekar, GK., Satyanarayan, K., Jagadeeswary, V., and Shilpashree, J. 2017. Relationship between SocioEconomic and Psychological Factors of Dairy Farmers with Days Open - A Study in Rural Karnataka. International Journal of Pure and Applied Bioscience, 5(1): 171-177.

Debasish, S., Afzal, H.A., and Abdul, H. 2010. Livestock Farmers Knowledge about Rearing Practices in Ganderbal district of Jammu \& Kashmir, Indian Journal of Extension Education, 10(2): 15-19.

Desai, HG. 2011. Dairy farming in South Gujarat: Problems and Remedies, Indian Journal of Dairy Science, 64(2): 162-167.

Gangasagare, P.T., and Karanjkar, L.M. 2009. Status of Milk Production and Economic Profile of Dairy Farmers in the Marathwada region of Maharashtra, Veterinary world, 2(8): 317-320.

Gautam, U.S., Ramchand, and Singh, DK. 2007. Socio - Personal Correlation of Decision Making and Adoption of Dairy Practices, Indian Research Journal Extension Education, 7(3): 1011.

Go A.P. 2015. Statistical Abstract of Andhra Pradesh, Directorate of Economics and Statistics, Government of Andhra Pradesh, Hyderabad.

GOI. 2017. State/UT wise Buffalo Milk Production in India from 2013-14 to 2015-16, Community.org.in. Open Government Data (ODG) Platform India, as accessed on 20/9/17.

Heffernan, C. 2002. The Delivery of Veterinary Services to the Poor: In (Eds) Morrenhof, J., Ahuja, V., Tripathy, A. Livestock services and the poor. Proceedings and the presentations of the International workshop held at Bhubaneswar, India: 51-60. 
Mande, J.V., and Thombre, B.M. 2009. Adoption of Cattle Rearing Practices by Owners in Latur district, Journal of Dairying Foods and Home Science, 28(3/4): 176-180.

Manohar, DS. 2012. Study on Managemental Practices of Buffaloes in Jaipur district of Rajasthan, M.V.Sc Thesis, Rajasthan University of Veterinary and Animal Sciences, Bikaner, Rajasthan.

Nataraju. 2012. A Study on Participation of Women in Dairy Farming in Chikkamagalore, M. Sc. Thesis, University of Agricultural Sciences, Bangalore.

NSS. 2013. Livestock Ownership in India, NSS $70^{\text {th }}$ round, Ministry of Statistics and Programme Implementation, Government of India.

Prasad, R.M.V., Rao, GN., and Krishna, VJR. 2001. Analysis on Milk Production from Buffaloes, Indian Veterinary Journal, 78(3):257-259.

Rathod, PK., Nikam, RT., Landge, S., and Hatey, A. 2013. Farmers Perception towards Delivery of Feed and Fodder by Dairy Cooperatives in Western Maharashtra, Indian Journal of Dairy Science, 66(3): 250-255.

Sinha, R.R.K., Dutt T., Bhushan, B., Singh, R.R., and Singh, M. 2009. Production and Reproduction Profile of Cattle and Buffaloes in Bareilly district of Uttar Pradesh, Indian Journal of Animal Sciences, 79(8): 786-787.
Sudhir, K.B. 2014. A Study on Rural Dairy Production System in Irrigated and Rain fed areas of Prakasam District of Andhra Pradesh, M.V.Sc. Thesis, Sri Venkateswara Veterinary University, Tirupati.

Suresh, B.D., Rao, K.S., Suresh, J., and Reddy, IS. 2013. Animal Husbandry Practices Adopted by Dairy Farmers Belonging to Different Production Systems, Indian Veterinary Journal, 90(6):54-56.

Swathi, Y. 2015. A Study on the Milking Management Practices and Quality of Milk in Rural and Urban areas of YSR Kadapa District, M.V.Sc. Thesis, Sri Venkateswara Veterinary University, Tirupati.

Upadhyay, M., and Yadav, CM. 2015. Involvement of Members and NonMembers of Women Dairy Cooperatives in Dairy Husbandry Activities, Indian Journal of Animal Production and Management, 31(1-2): 4-7.

Vinothini, M. 2010. A Study on Sustainability of Dairy Farming among the Members of Women Dairy Cooperative Societies in Puducherry, M.V.Sc. Thesis, Rajiv Gandhi College of Veterinary and Animal Sciences, Puducherry.

Waldie, K., and Ramkumar, S. 2002. Landless Women and Dairying. The Opportunities for Development within a Poverty Prospective, RAGACOVAS, Puducherry.

\section{How to cite this article:}

Sivaji, D.V., K. Natchimuthu, S. Ramkumar, D. Sreekumar and Ganesan, R. 2018. Socio Economic Profile of Buffalo Farmers in Guntur and Prakasam Districts of Andhra Pradesh, India. Int.J.Curr.Microbiol.App.Sci. 7(04): 1950-1955. doi: https://doi.org/10.20546/ijcmas.2018.704.223 